\title{
BMJ Open Hydrogen sulfide and traffic-related air pollutants in association with increased mortality: a case-crossover study in Reykjavik, Iceland
}

\author{
Ragnhildur Gudrun Finnbjornsdottir, ${ }^{1}$ Anna Oudin, ${ }^{2}$ Bjarki Thor Elvarsson, ${ }^{3}$ \\ Thorarinn Gislason, ${ }^{4,5}$ Vilhjalmur Rafnsson ${ }^{6}$
}

To cite: Finnbjornsdottir RG, Oudin A, Elvarsson BT, et al. Hydrogen sulfide and trafficrelated air pollutants in association with increased mortality: a case-crossover study in Reykjavik, Iceland. BMJ Open 2015;5:e007272. doi:10.1136/bmjopen-2014007272

- Prepublication history and additional material is available. To view please visit the journal (http://dx.doi.org/10. 1136/bmjopen-2014-007272).

Received 21 November 2014 Revised 10 March 2015 Accepted 12 March 2015

CrossMark

For numbered affiliations see end of article.

Correspondence to Dr Vilhjálmur Rafnsson; vilraf@hi.is

\section{ABSTRACT}

Objectives: To study the association between daily mortality and short-term increases in air pollutants, both traffic-related and the geothermal source-specific hydrogen sulfide $\left(\mathrm{H}_{2} \mathrm{~S}\right)$.

Design: Population-based, time stratified casecrossover. A lag time to 4 days was considered. Seasonal, gender and age stratification were calculated. Also, the best-fit lag when introducing $\mathrm{H}_{2} \mathrm{~S}>7 \mu \mathrm{g} / \mathrm{m}^{3}$ was selected by the Akaike Information Criterion (AIC).

Setting: The population of the greater Reykjavik area ( $n=181$ 558) during 2003-2009.

Participants: Cases were defined as individuals living in the Reykjavik capital area, 18 years or older ( $N=138657$ ), who died due to all natural causes (ICD-10 codes A00-R99) other than injury, poisoning and certain other consequences of external causes, or cardiovascular disease (ICD-10 codes 100-199) during the study period.

Main outcome measure: Percentage increases in risk of death (IR\%) following an interquartile range increase in pollutants.

Results: The total number of deaths due to all natural causes was 7679 and due to cardiovascular diseases was 3033 . The interquartile range increased concentrations of $\mathrm{H}_{2} \mathrm{~S}\left(2.6 \mu \mathrm{g} / \mathrm{m}^{3}\right)$ were associated with daily all natural cause mortality in the Reykjavik capital area. The $I R \%$ was statistically significant during the summer season (lag 1: IR\% $=5.05,95 \% \mathrm{Cl} 0.61$ to 9.68; lag 2: IR\%=5.09, $95 \% \mathrm{Cl} 0.44$ to 9.97$)$, among males (lag 0: IR\%=2.26, $95 \% \mathrm{Cl} 0.23$ to 4.44 ), and among the elderly (lag $0: \mathrm{IR} \%=1.94,95 \% \mathrm{Cl} 0.12$ to 1.04; lag 1: IR\%=1.99, $95 \% \mathrm{Cl} 0.21$ to 1.04 ), when adjusted for traffic-related pollutants and meteorological variables. The traffic-related pollutants were generally not associated with statistical significant IR\%s.

Conclusions: The results suggest that ambient $\mathrm{H}_{2} \mathrm{~S}$ air pollution may increase mortality in Reykjavik, Iceland. To the best of our knowledge, ambient $\mathrm{H}_{2} \mathrm{~S}$ exposure has not previously been associated with increased mortality in population-based studies and therefore the results should be interpreted with caution. Further studies are warranted to confirm or refute whether $\mathrm{H}_{2} \mathrm{~S}$ exposure induces premature deaths.

\section{Strength and limitations of this study}

- The study is population-based and relies on comprehensive Icelandic population registries.

- The death registration quality is high overall, with $100 \%$ completeness.

- The methodology allows within-subject comparison while adjusting for various time trends such as seasonality and day of week.

- Only one air quality measuring station used as a proxy for exposure of air pollutants for every individual of the whole capital area.

- The Icelandic population is small and therefore, the total number of cases were few, which results in low statistical power.

\section{INTRODUCTION}

A few studies have been conducted in Reykjavik, Iceland, on the possible health effects of air pollution. ${ }^{1-3}$ It is rumoured that the Reykjavik capital area is one of the cleanest cities in the world; ${ }^{1}$ however, daily levels of hydrogen sulfide $\left(\mathrm{H}_{2} \mathrm{~S}\right)$ and particle matter have been positively associated with the use of drugs for obstructive pulmonary disease. ${ }^{1}$ Later Reykjavik studies indicated an association between ozone $\left(\mathrm{O}_{3}\right)$ and cardiopulmonary and stroke emergency hospital visits, ${ }^{3}$ and association of nitrogen dioxide $\left(\mathrm{NO}_{2}\right)$ and $\mathrm{O}_{3}$ with sales of glyceryl trinitrate for use against angina pectoris. ${ }^{2}$

The ambient air pollution in Reykjavik is not only due to traffic-related emissions from the high density of cars. ${ }^{4}$ In addition, two geothermal power plants, located approximately 26 and $33 \mathrm{~km}$ east of the city, are the main point sources of intermittent $\mathrm{H}_{2} \mathrm{~S}$ concentrations in the city. ${ }^{56}$ The combined $\mathrm{H}_{2} \mathrm{~S}$ emissions from the two geothermal power plants ranged from 7224 tons/year in 2003 to 20756 tons/year in $2009 .^{7}$ Health effects of $\mathrm{H}_{2} \mathrm{~S}$ exposure from geothermal sources 
are to some extent known $^{8}$ and long-term, low-level exposure to $\mathrm{H}_{2} \mathrm{~S}$ adversely effects respiratory health, according to studies from different locations. ${ }^{9} 10$ However, a recent study in Rotorua, New Zealand, did not find an increased asthma risk associated with $\mathrm{H}_{2} \mathrm{~S}$ exposure. ${ }^{11}$ Another study in Rotorua showed increased mortality due to respiratory diseases; however, those results were possibly confounded by ethnicity. ${ }^{12}$

The setting in the Reykjavik capital area with access to nation-wide death registry and continuous measurements of ambient air pollutants offers an opportunity to study the association of short-term increases in the traffic-related pollutants $\mathrm{NO}_{2}, \mathrm{O}_{3}, \mathrm{PM}_{10}, \mathrm{SO}_{2}$ and in particular, the geothermal source-specific $\mathrm{H}_{2} \mathrm{~S}$ with mortality.

\section{MATERIALS AND METHODS}

Site description

The city of Reykjavik is the world's northernmost capital of a sovereign state. Located in south-western Iceland, on the southern shore of the Faxafloi bay, the greater area of Reykjavik covers $247.5 \mathrm{~km}^{2}$ and is divided into seven smaller communities. The main sources of air pollution in the city are traffic-related pollutants and emission from two geothermal power plants located 26 and $33 \mathrm{~km}$ east of the city. The larger power plant Hellisheidarvirkjun (26 km from the city) started operating in September 2006; the Nesjavallavirkjun power plant had started operating in 1990.

Over the study period, 1 January 2003-31 December 2009, the annual mean population of the greater Reykjavik area was 181558 individuals $(49.7 \%$ males and $50.3 \%$ females). ${ }^{13}$ The study base consisted of inhabitants of the greater Reykjavik area living in one of the following communities (identified by postal codes): Alftanes, Gardabaer, Hafnarfjordur, Kopavogur, Mosfellsbaer, Reykjavik or Seltjarnarnes. The study included individuals who were 18 years and older $(\mathrm{N}=138657){ }^{13}$

\section{Case ascertainment}

Statistics Iceland maintains the National Cause-of-Death Registry under the auspices of the Directorate of Health. The registry is nation-wide and includes causes of death according to death certificates classified by the International Classification of Diseases, Revision 10 (ICD-10).${ }^{14}$ Data were obtained from the registry on cardiovascular mortality only (ICD-10 codes I00-I99) and all natural cause mortality (cardiovascular mortality included; ICD-10 codes A00-R99) other than injury, poisoning and certain other consequences of external causes. During the study period, the average number of deaths per year due to diseases of the respiratory system (ICD-10 codes J00-J99) was 161.6 and therefore, too few to make meaningful calculation due to lack of power. The data also contained information on encrypted personal identification number, day of death, age at time of death, postal codes and gender of the deceased.
Finally, two preconditions were needed to be defined as a case: (1) the individual was living in the Reykjavik capital area on the day of death in one of the aforementioned communities, and (2) the individual was 18 years or older.

\section{Exposure and covariate assessment}

Exposure data were obtained from the Environment Agency of Iceland (EAI). The agency operates an air pollution measurement station located at one of Reykjavik's main road intersections (GrensasvegurMiklabraut), where around 60000 cars on average cross the intersection each day. ${ }^{15}$ Hourly concentrations were obtained for $\mathrm{NO}_{2}, \mathrm{O}_{3}, \mathrm{PM}_{10}, \mathrm{SO}_{2}$ and $\mathrm{H}_{2} \mathrm{~S}$ measured as $\mu \mathrm{g} / \mathrm{m}^{3}$. Data on meteorological variables (temperature $\left({ }^{\circ} \mathrm{C}\right)$, relative humidity $(\mathrm{RH})$ ) were derived from the same measurement station. Monthly numbers of influenza cases were obtained from the Directorate of Health. The influenza season was defined as 300 cases/ month and introduced as a dichotomous variable.

$\mathrm{NO}_{2}$ and $\mathrm{O}_{3}$ were measured with a Horiba (models APNA 360E and APSA 360ACE) device, $\mathrm{PM}_{10}$ with an Andersen EMS IR Thermo (model FH62 I-R), and $\mathrm{SO}_{2}$ and $\mathrm{H}_{2} \mathrm{~S}$ were measured with the same device, Horiba (model APOA 360E). The devices are calibrated every 6-12 months. Some gaps in the data were evident, which is attributed to inactive measurement devices for various unknown reasons.

The data set pertained to 7 years or 2557 days. The $24 \mathrm{~h}$ average parameter was calculated for each pollutant using the hourly concentrations from midnight to midnight the following day, where at least $75 \%$ of the $1 \mathrm{~h}$ data existed. Missing $24 \mathrm{~h}$ values for $\mathrm{NO}_{2}, \mathrm{O}_{3}$ and $\mathrm{PM}_{10}$ were 183 days $(7 \%), 230$ days $(9 \%)$ and 65 days (3\%), respectively. $\mathrm{SO}_{2}$ measurements started on 3 January 2004 and $\mathrm{H}_{2} \mathrm{~S}$ on 22 February 2006; so the exposure information for these pollutants was available for a shorter time span than the others, contributing to 2190 and 1408 days in the data set, respectively. The missing data for these pollutants over the study period were 145 days $(7 \%)$ for $\mathrm{SO}_{2}$ and 156 days $(11 \%)$ for $\mathrm{H}_{2} \mathrm{~S}$. Temperature and RH measurement started on 1 January 2004, thus contributing to 2192 days in the data set. The missing data were 42 days (2\%) for the two factors. Most unavailable values were in 2003 , but otherwise the missing values were random and not associated with any specific day of the week. Gaps in the data due to missing values were filled by linear interpolation of adjacent values.

Descriptive statistics were calculated for the $24 \mathrm{~h}$ average concentrations of environmental data. To evaluate the intercorrelation between exposure variables and meteorological covariates, Spearman's correlation test was used.

\section{Design and data analysis}

A case-crossover design was used to estimate the association of short-term daily exposure of air pollution with all natural cause and cardiovascular mortality by 
applying a time-stratified referent selection approach. We divided the study period into monthly strata and the exposure of the case day (index day) was compared with the exposure of the control days, which were matched on the same day of the week within the same stratum. This would give a maximum of four control days per case. ${ }^{1617}$ Both single pollutant models and multivariate models (containing all pollutants and meteorological factors) were calculated; separate models were used for all natural cause, and cardiovascular mortality. There was a seasonal difference in the concentrations of the pollutants and 80 years of age is a proxy for the mean age at death. Separate analyses were performed by stratifying on season (winter: 1 November-30 April, summer: 1 May-31 October), gender, age ( $\geq 80$ and $<80$ years). We used conditional logistic regression giving adjusted ORs and 95\% CIs scaled to the IQR increase of the $24 \mathrm{~h}$ concentration level of each pollutant. All multivariate models were adjusted for temperature and RH. Results will be shown as percentage increases in risk of death (IR\%).

A lag time of up to 4 days (five lags: $0-4$ ) was introduced separately to the analyses. Lag definitions are as follows: lag 0: air pollution exposure on the same day as death occurred, lag 1-4: air pollution exposure 1 day before (lag 1) and up to 4 days before (lag 4) the death occurred.

A number of supplementary analyses were conducted. First, the time-stratified approach was applied by dividing the study period into 2-month strata using a referent selection matched on the same day of the week with 14-day intervals within the same stratum as the case day. Second, models using 1 and 2 months strata were also run by introducing the 3-day running averages of each environmental factor, separately. All analyses were adjusted for influenza season; however, this was omitted from the single and multivariate analyses as introducing these did not change the risk. The results for these analyses will not be presented here as they were practically identical to the presented results and are available on request.

A principal component analysis was conducted on the pollutant data set after 6 January 2003 to the end of the study period, ${ }^{18}$ prior to the selection of the best model. The Akaike Information Criterion (AIC) ${ }^{19}$ was used to select the lag model with the lowest AIC from the series of lags $0-4$, when components $1-8$, season, influenza and $\mathrm{H}_{2} \mathrm{~S}$ above $7 \mu \mathrm{g} / \mathrm{m}^{3}$ were entered into the model. The $\mathrm{H}_{2} \mathrm{~S}$ above $7 \mu \mathrm{g} / \mathrm{m}^{3}$ was chosen because of the right skewed distribution of the $\mathrm{H}_{2} \mathrm{~S}$ concentration and this limit is considered as the odour limit for $\mathrm{H}_{2} \mathrm{~S} .^{20}$

R V.3.0.3 was used for all statistical analyses. ${ }^{21}$ Within $\mathrm{R}$, the 'season' package ${ }^{22}$ was used to perform the timestratified case-crossover analysis. All statistical tests applied in the study were two-tailed and we considered statistically significant all results with $\mathrm{p}<0.05$.

The study protocol was approved by the National Bioethics Committee (ref. no. VSNb2010030008/03.7) and the Data Protection Authority (ref. no. 2010030263 PS/-).

\section{RESULTS}

\section{Description of the mortality and the environmental data}

The total numbers of deaths due to all natural cause death and from cardiovascular diseases in the greater Reykjavik area during the study period were 7679 and 3033 cases, respectively, where the gender rate was just about equal in both cases. On average, there were 3.2 and 1.7 deaths due to all natural causes and cardiovascular diseases, respectively, each day. The average age at death of individuals who died of all natural causes was 78 years (males: 76 years; females: 80 years). For individuals who died due to a cardiovascular event, the average age at death was 81 years (males: 78 years; females: 84 years; table 1 ).

The distributions of the environmental variables are presented in table 2. Pollution data completeness varied from $48.9 \%\left(\mathrm{H}_{2} \mathrm{~S}\right)$ to $97.5 \%\left(\mathrm{PM}_{10}\right.$; table 2$)$. There was a seasonal pattern among each pollutant and meteorological variable. The mean for each pollutant was higher during the winter months of November-April than during the summer months May-October. The concentration range for $\mathrm{PM}_{10}$ was the largest, followed by $\mathrm{NO}_{2}$. Daily $\mathrm{SO}_{2} 24 \mathrm{~h}$ average concentration was often low with a small range up to $11.0 \mu \mathrm{m} / \mathrm{m}^{3}$; only $5 \%$ of the $24 \mathrm{~h}$

\begin{tabular}{|c|c|c|c|c|c|}
\hline & Mortality n (\%) & Range (years) & $\begin{array}{l}\text { Mean age } \\
\text { at death }\end{array}$ & \pm SD & $\begin{array}{l}\text { Number of } \\
\text { deaths per } 24 \mathrm{~h}\end{array}$ \\
\hline \multicolumn{6}{|c|}{ All natural causes (ICD-10 codes A-R) } \\
\hline Total & $7679(100)$ & 18-109 & 78 & 13.1 & 3.2 \\
\hline Men & 3711 (48.3) & $18-108$ & 76 & 13.2 & 1.5 \\
\hline Female & $3968(51.7)$ & $18-109$ & 80 & 12.7 & 1.6 \\
\hline \multicolumn{6}{|c|}{ Disease of the circulatory system (ICD-10 codes 100-199) } \\
\hline Total & $3033(100)$ & $18-105$ & 81 & 11.4 & 1.7 \\
\hline Men & 1545 (50.9) & $18-102$ & 78 & 12.2 & 0.9 \\
\hline Female & $1488(49.1)$ & 18-105 & 84 & 9.9 & 0.8 \\
\hline
\end{tabular}




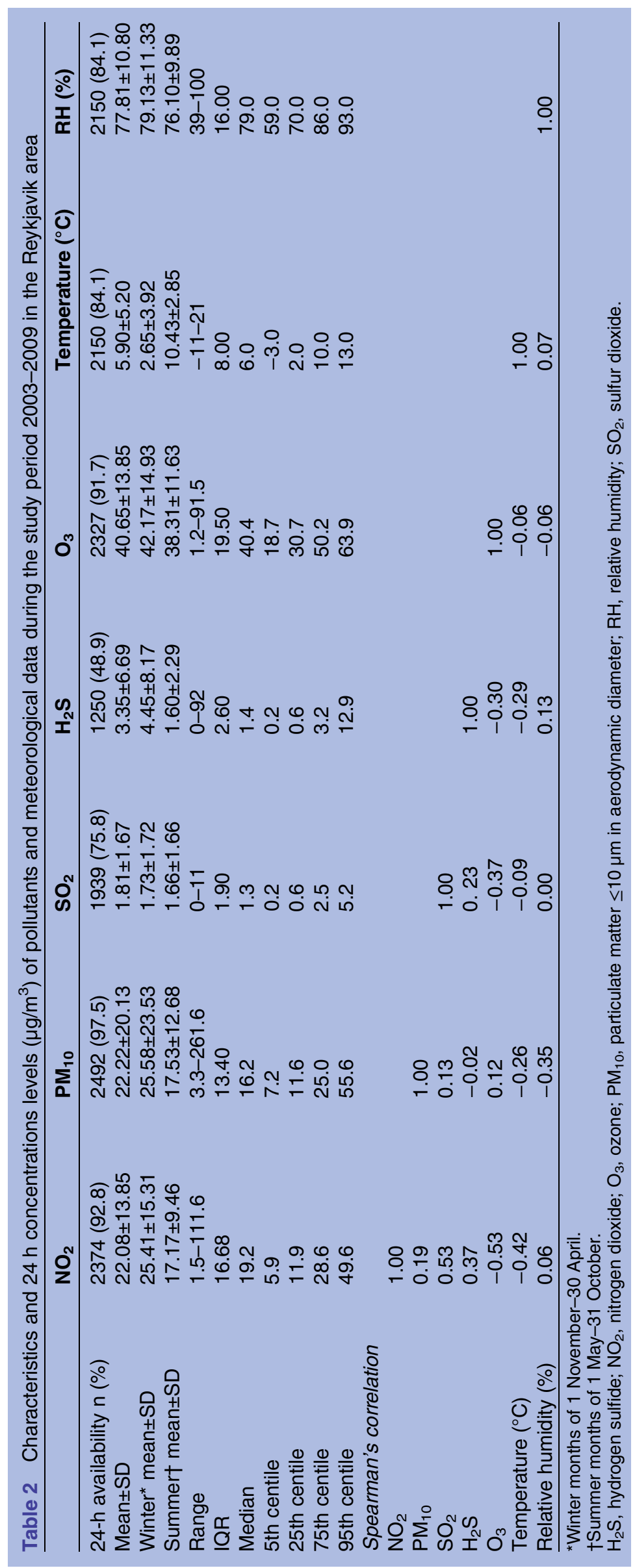


values were above $5.3 \mu \mathrm{g} / \mathrm{m}^{3}$. The highest value of the IQR was for $\mathrm{O}_{3}$ and lowest for $\mathrm{SO}_{2}$. For $\mathrm{H}_{2} \mathrm{~S}$, the IQR was quite low $\left(2.60 \mu \mathrm{g} / \mathrm{m}^{3}\right)$ although the maximum value was around $92 \mu \mathrm{g} / \mathrm{m}^{3}$ (figure 1 ).

The pairwise correlation coefficients for $24 \mathrm{~h}$ mean pollutants and meteorological variables are shown in table 2. The strongest positive correlation was between $\mathrm{NO}_{2}$ and $\mathrm{SO}_{2}$ (0.53). The strongest negative association was between $\mathrm{NO}_{2}$ and $\mathrm{O}_{3}$. The weakest correlation was between $\mathrm{PM}_{10}$ and other pollutant factors. $\mathrm{H}_{2} \mathrm{~S}$ was correlated with $\mathrm{NO}_{2}, \mathrm{SO}_{2}$ and $\mathrm{O}_{3}$. Temperature was inversely correlated with all pollutants. $\mathrm{RH}$ was weakly correlated with most pollutants; however, the strongest correlation was -0.35 with $\mathrm{PM}_{10}$ (table 2 ).

\section{All natural cause death}

Table 3 shows the percentage increases in risk of all natural cause death (ICD-10 codes A00-R99), other than injury, poisoning and certain other consequences of external causes, associated with $\mathrm{IQR}$ increases of the $24 \mathrm{~h}$ mean concentrations of each pollutant in multivariate analyses.

The results are shown in models that were unstratified and stratified on season, gender and age. The analyses of $\mathrm{H}_{2} \mathrm{~S}$ showed a certain pattern which is not observed for the other pollutants. In the unstratified model, there was an increased risk at lag 0 and 1 which was not statistically significant; however, and at lag 3 there was a statistically significant decrease. During the summer months there was increased risk at lag 0 and statistically significant increased risk at lag 1 and 2. During the winter months, there was a statistically significant decreased risk at lag 3, corresponding to the increase during the summer months. For males, there was an increased risk at lag 0 . For individuals, who were 80 years of age and older, there was a statistically significant increased risk at lag 0 and lag 1 , and among individuals younger than 80 years of age there was a statistically significant decrease at lag 2. For $\mathrm{O}_{3}$ there was a statistically significant decreased risk at lag 3 in the unstratified and summer models. For $\mathrm{SO}_{2}$ there was a statistically significant increased risk at lag 4 in the winter models. For
$\mathrm{NO}_{2}$ there was a statistically significant decreased risk at lag 1 and lag 4 for males and females, respectively. For $\mathrm{PM}_{10}$ there was statistically significant increased risk at lag 0 for individuals younger than 80 years of age.

The single pollutant models for all natural cause death gave a similar pattern for $\mathrm{H}_{2} \mathrm{~S}$; however, in many statistically significant lags in the multivariate models, the CIs were wider and included unity in the single pollutant models (see online supplementary table S1).

\section{Cardiovascular death}

Online supplementary tables S2 and S3 show the percentage increases in risk in cardiovascular diseases (ICD-10 codes I00-I99) associated with IQR increases of the $24 \mathrm{~h}$ mean concentrations of each pollutant in single pollutant and multivariate models that were unstratified and stratified on season, gender and age.

In the multivariate models (see online supplementary table S2) there was a significant increased risk at lag 0 for $\mathrm{PM}_{10}$ and $\mathrm{SO}_{2}$ for those younger than 80 years of age as well as at lag 1 for $\mathrm{SO}_{2}$. For individuals 80 years and older there was a statistically significant decrease at lag 1 for the same pollutants corresponding to the increase among individuals younger than 80 years of age. Additionally, the analysis of $\mathrm{SO}_{2}$ showed a significant increased risk among females at lag 4 and during winter months at lag 1 for $\mathrm{PM}_{10}$ (see online supplementary table S2).

In the single pollutant models (see online supplementary table S3) for cardiovascular diseases, the CIs were wide and all included unity except for $\mathrm{PM}_{10}$ and $\mathrm{SO}_{2}$ for individuals younger than 80 years of age at lag 0 .

\section{Model selection}

The factor loadings of the principal components for pollutants are shown in table 4 . The first component is mainly humidity, the second is a combination of $\mathrm{NO}_{2}$ and $\mathrm{PM}_{10}$, and the third appears to capture the inverse correlation between $\mathrm{NO}_{2}$ and $\mathrm{O}_{3}$ observed in table 2 . Other components are a combination of a larger number of pollutants, where the fourth component is mainly the combination of $\mathrm{O}_{3}$ and $\mathrm{NO}_{2}$, the fifth
Figure 1 Distribution of $24 \mathrm{~h}$ average concentrations of hydrogen sulfide $\left(\mathrm{H}_{2} \mathrm{~S}\right)$ in $\mu \mathrm{g} / \mathrm{m}^{3}$ in Reykjavik, Iceland, over the study period of 1 January 2003-31 December 2009. $\mathrm{H}_{2} \mathrm{~S}$ measurements started in February 2006. Gaps in figure are due to missing data.

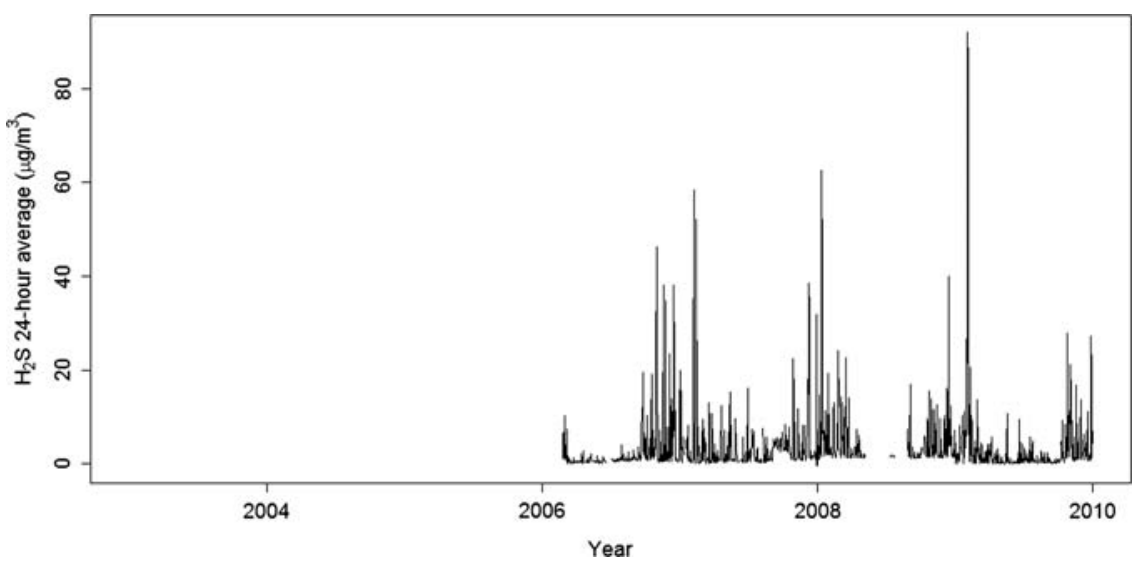




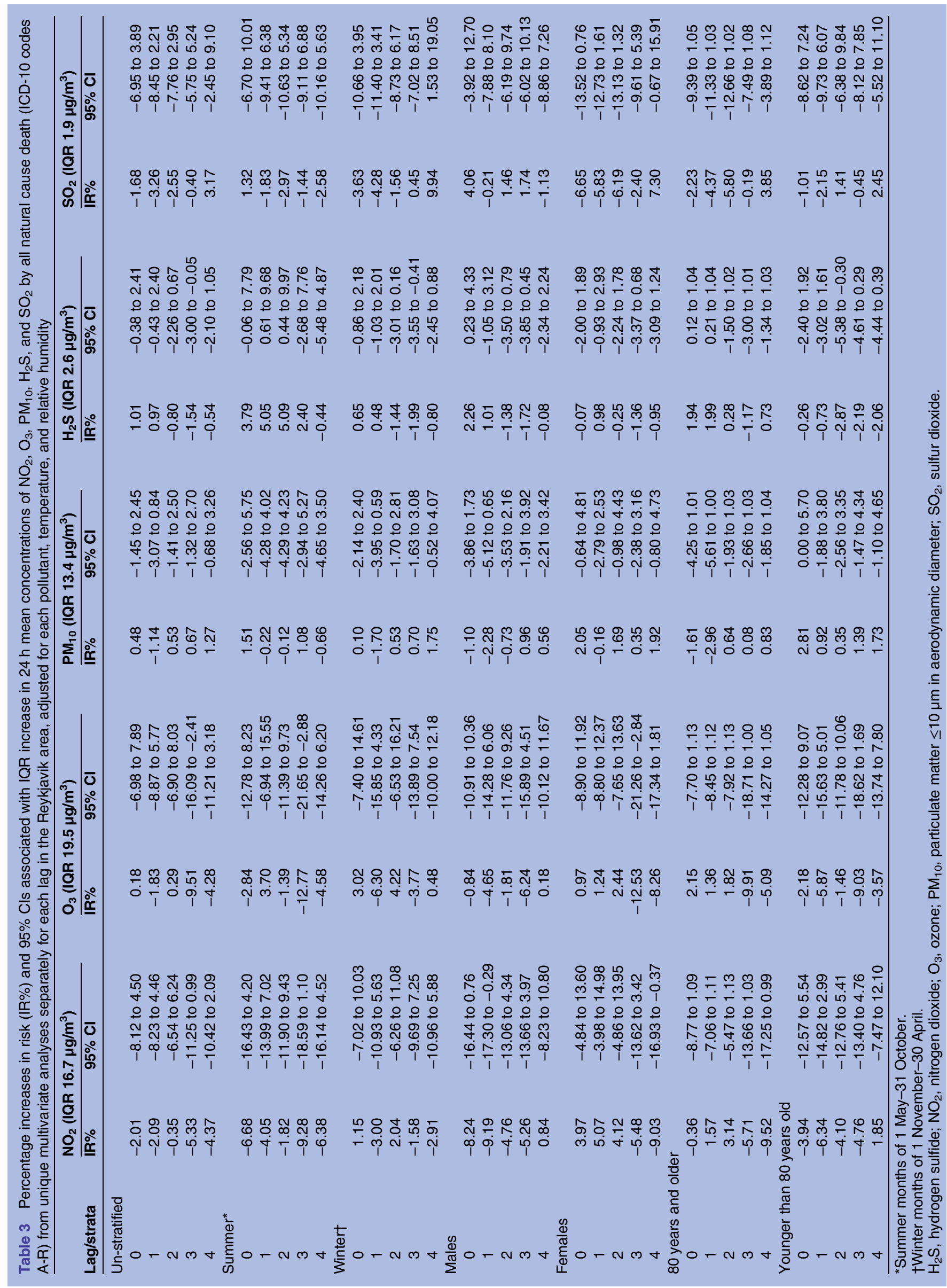




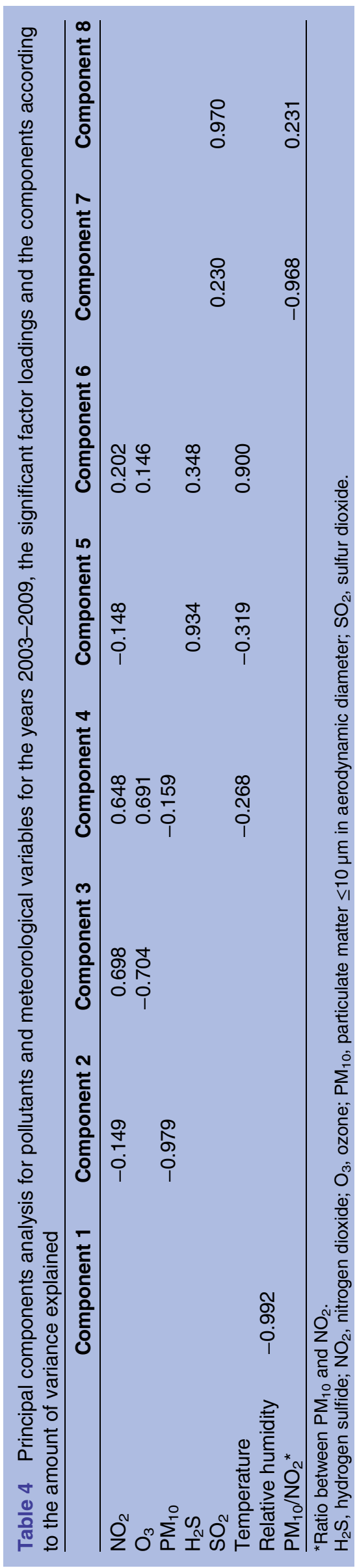

component is mainly effects of $\mathrm{H}_{2} \mathrm{~S}$ and the eighth component appears to follow $\mathrm{SO}_{2}$ linearly.

Among all lags, the best models are at lag 3 (3 parameters, AIC value 42158.86 ) and at lag 2 (2 parameters, $\mathrm{AIC}$ value 42160.84 ) with delta $\mathrm{AIC}=1.98$. The percentage increases in risk of all natural cause death is shown in table 5 for these two lags. At lag 3, the IR\% associated with component 4 appeared with decreased risk, which is not statistically significant. However, $\mathrm{H}_{2} \mathrm{~S}$ above $7 \mu \mathrm{g} / \mathrm{m}^{3}$ was with decreased risk, $p$ value of 0.022 . Interaction between season (summer) and component $4 \quad\left(\mathrm{NO}_{2}\right.$ : 0.648; $\mathrm{O}_{3}$ : 0.691; $\mathrm{PM}_{10}$ : -0.159; temperature: -0.268$)$ was decreased, and interaction between season (summer) and $\mathrm{H}_{2} \mathrm{~S}$ above $7 \mu \mathrm{g} / \mathrm{m}^{3}$ was increased and these were significant with $\mathrm{p}$ values of 0.042 and 0.015 , respectively. According to the OR for all natural cause death associated with $\mathrm{H}_{2} \mathrm{~S}$ in the model at lag 3 , the increased risk is 16.54 when $\mathrm{H}_{2} \mathrm{~S}$ exceeded $7 \mu \mathrm{g} / \mathrm{m}^{3} 3$ days before. At lag 2, the IR\% associated with $\mathrm{H}_{2} \mathrm{~S}$ above $7 \mu \mathrm{g} / \mathrm{m}^{3}$ was with decreased risk, $p$ value of 0.004 . Interaction between season (summer) and $\mathrm{H}_{2} \mathrm{~S}$ above $7 \mu \mathrm{g} / \mathrm{m}^{3}$ was increased and was significant with $\mathrm{p}$ values of 0.006 . According to the OR for all natural cause death associated with $\mathrm{H}_{2} \mathrm{~S}$ in the model, at lag 2 the increased risk is 16.59 when $\mathrm{H}_{2} \mathrm{~S}$ exceeded $7 \mu \mathrm{g} / \mathrm{m}^{3} 2$ days before.

The results for all lags are shown in online supplementary table $\mathrm{S} 4$.

\section{DISCUSSION}

We found associations between increased concentration of $\mathrm{H}_{2} \mathrm{~S}$ and daily all natural cause death in the Reykjavik area. These associations were strong and statistically significant during summer months (lag 1 and lag 2), among males (lag 0 ), and among the elderly (lag 0 and lag 1) when adjusted for traffic-related pollutants and meteorological variables. The pattern seen of percentage increases in risk of death associated with increased concentration of $\mathrm{H}_{2} \mathrm{~S}$ is compatible with harvesting effect, that is, increased risk at lower lags (0-2), and decreased risk at higher lag (3) through the unstratified and stratified analyses. The results from the model selection support these findings as they show an interaction between $\mathrm{H}_{2} \mathrm{~S}$ exposure, season (summer), and some traffic-related pollutants at lag 3 and lag 2. The results from the principle components analysis were used in the model selection. Death due to diseases of the circulatory system showed a similar pattern, but the associations were weaker. The $\mathrm{H}_{2} \mathrm{~S}$ pollution in the Reykjavik area originates from two geothermal power plants located 26-33 km east of the city. In the present study, we did not find the well-known association between traffic-related pollutants and mortality, and it should be noted that the concentrations are low and the population is small.

Bates $e t a l^{12}$ found increased respiratory disease mortality among Maori females in the geothermal area of Rotorua compared to mortality in New Zealand. The authors mention the possibility of uncontrolled 
Table 5 Percentage increases in risk (IR\%), 95\% Cls, and $p$ values by all natural cause death during 2003-2009 in the Reykjavik area, at lag 2 and 3, the best models according to the Akaike Information Criterion

\begin{tabular}{|c|c|c|c|}
\hline $\begin{array}{l}\text { Components/ } \\
\text { parameters }\end{array}$ & IR\% & $95 \% \mathrm{Cl}$ & p Value \\
\hline \multicolumn{4}{|l|}{ Lag 2} \\
\hline Summer* & 5.30 & -16.88 to 33.50 & 0.670 \\
\hline $\begin{array}{l}\mathrm{H}_{2} \mathrm{~S}\left(>7 \mu \mathrm{g} / \mathrm{m}^{3}\right) \\
\text { Interaction terms }\end{array}$ & -18.75 & -29.49 to -6.39 & 0.004 \\
\hline $\begin{array}{l}\text { Summer: } \mathrm{H}_{2} \mathrm{~S} \\
\left(>7 \mu \mathrm{g} / \mathrm{m}^{3}\right)\end{array}$ & 43.50 & 11.10 to 85.50 & 0.006 \\
\hline \multicolumn{4}{|l|}{ Lag 3} \\
\hline Summer* & 4.00 & -14.77 to 27.00 & 0.698 \\
\hline Component 4† & -0.12 & -0.71 to 0.50 & 0.704 \\
\hline $\begin{array}{l}\mathrm{H}_{2} \mathrm{~S}\left(>7 \mu \mathrm{g} / \mathrm{m}^{3}\right) \\
\text { Interaction terms }\end{array}$ & -14.87 & -25.80 to -2.33 & 0.022 \\
\hline $\begin{array}{l}\text { Summer: } \\
\text { Component } 4\end{array}$ & -0.95 & -1.86 to -0.04 & 0.042 \\
\hline $\begin{array}{l}\text { Summer: } \mathrm{H}_{2} \mathrm{~S} \\
\left(>7 \mu \mathrm{g} / \mathrm{m}^{3}\right)\end{array}$ & 36.90 & 6.20 to 76.50 & 0.015 \\
\hline
\end{tabular}

confounding by ethnicity in their study ${ }^{12}$ and there was a known difference in smoking habits by ethnicity. Later studies of Rotorua population showed an increase in circulatory diseases and chronic health effects related to $\mathrm{H}_{2} \mathrm{~S}$ exposure. ${ }^{23}{ }^{24}$ A still later ecological study from Rotorua, using a hospital discharge registry, found increased association between $\mathrm{H}_{2} \mathrm{~S}$, and respiratory diseases and symptoms. ${ }^{9}$

Inhabitants of volcanic areas have been found to have a high incidence of chronic bronchitis compared with those not exposed to volcanic environments and these findings may be attributed to exposure to $\mathrm{H}_{2} \mathrm{~S}$ or $\mathrm{SO}_{2}{ }^{25}$ As previously mentioned, $\mathrm{H}_{2} \mathrm{~S}$ has been described in volcanic environments ${ }^{8}$ and is primarily considered an upper respiratory irritant. Neurological effects and fatal intoxication have also been related to high $\mathrm{H}_{2} \mathrm{~S}$ exposures $^{825}$ and among the deadly intoxications, a fatal case was reported in a geothermal power plant. ${ }^{26}$

For exposure to $\mathrm{H}_{2} \mathrm{~S}$ in settings other than volcanic environment, the potential health effects among sewer, oil and gas workers, general population located near a pulp mill, industrial wastewater plants, geothermal energy production and industrial swine operations ${ }^{27-29}$ have been studied. These studies have reported on respiratory symptoms, decreased performance on pulmonary functions tests and increased respiratory diseases. More recent studies on populations near industrial swine operations, slaughter and tanning facilities and wastewater treatment complexes exposed to low-level $\mathrm{H}_{2} \mathrm{~S}$ report odour nuisance and an increase in hospital visits due to respiratory diseases. ${ }^{30}{ }^{31}$ Finally, a study on workers exposed to low-level $\mathrm{H}_{2} \mathrm{~S}$ from various industries found this study group to have impaired neurobehavioral functions, ${ }^{32}$ a finding that was considered to match reports on neurological squeal among survivors of serious $\mathrm{H}_{2} \mathrm{~S}$ intoxications. On the contrary, chronic $\mathrm{H}_{2} \mathrm{~S}$ exposure was not associated with impaired cognitive function in a study of the population in Rotorua. $^{33}$

In a recent Icelandic long-term follow-up study among residents of geothermal areas who had been using the hot geothermal water for space heating, washing and bathing (not as drinking water), increased mortality was found for several cancer types, including non-Hodgkin's lymphoma, breast, prostate and kidney cancers, as well as influenza and suicide. ${ }^{34}$ This study had a different approach, as compared to the present one, as it mainly aimed to confirm previously found increased cancer incidence ${ }^{35} 36$ however, the population was evidently exposed to low level $\mathrm{H}_{2} \mathrm{~S}$.

In summary, ambient $\mathrm{H}_{2} \mathrm{~S}$ in unpolluted areas are 0.03 to $0.4 \mu \mathrm{g} / \mathrm{m}^{3}$. Reports on adverse health effects of $\mathrm{H}_{2} \mathrm{~S}$ on humans come from acute incidents and occupational studies as population-based studies are few. The odour threshold varies and is often estimated at $7 \mu \mathrm{g} / \mathrm{m}^{3}$; olfactory paralysis occurs at concentrations higher than $140 \mathrm{mg} / \mathrm{m}^{3}$, while exposure at $700 \mathrm{mg} / \mathrm{m}^{3}$ for a short period of time (few breaths) can be fatal. Short-term exposure to high concentration causes effects in different systems, the most important being the respiratory, neurological and ocular effects. Increased mortality has not previously been associated with low levels $\left(100 \mu \mathrm{g} / \mathrm{m}^{3}\right) .^{25}$

The main strength of this study is that it is populationbased and relies on the comprehensive population registries, the National Registry, for the information on the postal codes of the inhabitants of the Reykjavik area and the nation-wide Cause-of-Death Registry for the mortality data. The use of the personal identification numbers of every Icelandic individual in the registries precluded double counting of individuals and events.

In Iceland, death certificates are issued by a physician. According to a study at a global level on the quality of the death registration, the data from Iceland was categorised as of high quality overall and classified with data from 23 developed countries, including US and UK. ${ }^{37}$

Another strength of the present study is the methodology, the time-stratified case-crossover approach, which allows within-subject comparison while adjusting for various time trends such as seasonality and day of week.

The pollution from the volcanic eruption of the Eyjafjallajökull in 2010 is not confounding the results of the present study as that event occurred after the study period. $^{38} 39$

A few limitations to this study should be mentioned. One is that the pollution data is derived from only one measurement station in Reykjavik rather than containing data on individual exposure. This station was, thus, used as a proxy for exposure of air pollutants for the death of individuals in the whole capital area although meteorological factors, such as wind speed and direction, cloud cover, precipitation and geographical distribution, are 
known to affect air pollution concentrations. This is especially true for $\mathrm{H}_{2} \mathrm{~S}$, where concentrations of $\mathrm{H}_{2} \mathrm{~S}$ depend on various meteorological factors. ${ }^{5}{ }^{40}$ Many calculations performed in the present study may give rise to concern due to multiple comparisons; however, it has been argued that no adjustments are needed for these. ${ }^{41}$ The increased risk seemed to be restricted to the oldest in the population and the data consisted of those 18 years of age and older, limiting the generalisability of the results with regard to age. Another limitation is the small number of cases, especially with regard to cardiovascular mortality, which are statistically underpowered. This can lead to wide CIs and uncertain conclusions. This is an inherent weakness for small populations such as Iceland. Also, cause of death in this study was only based on the primary cause mentioned in the death registries. Secondary causes, from the death certificates, were not available. In this study, the main focus has been on all natural cause mortality, which is a wide and heterogeneous category and it would be desirable to study this association according to cause-specific mortality in a larger data. Furthermore, there may be possible misclassification concerning cause of death; however, this is perhaps unlikely when the whole category of all natural cause deaths is the issue. Finally, the exact hour of death was not included in the mortality data and therefore, the possibility that the time of death may have preceded the exposure increase at lag 0 could not be ruled out.

\section{CONCLUSIONS}

The results from this study indicate an increase in mortality following an increase in $\mathrm{H}_{2} \mathrm{~S}$ concentrations $\left(2.6 \mu \mathrm{g} / \mathrm{m}^{3}\right)$, especially if the $24 \mathrm{~h}$ concentrations exceed $7 \mu \mathrm{g} / \mathrm{m}^{3}$ during summer months. Ambient $\mathrm{H}_{2} \mathrm{~S}$ exposure has been associated with increased cardiovascular and respiratory morbidity; however, to the best of our knowledge, increased mortality associated with $\mathrm{H}_{2} \mathrm{~S}$ exposure among the general population has not been previously reported. Therefore, the results have to be interpreted with caution. Further studies and improved methodology are warranted to confirm or refute whether $\mathrm{H}_{2} \mathrm{~S}$ exposure induces premature deaths.

\author{
Author affiliations \\ ${ }^{1}$ Centre of Public Health Sciences, University of Iceland, Reykjavik, Iceland \\ ${ }^{2}$ Occupational and Environmental Medicine, Department of Public Health and \\ Clinical Medicine, Umeå University, Umeå, Sweden \\ ${ }^{3}$ Science Institute, University of Iceland, Reykjavik, Iceland \\ ${ }^{4}$ Faculty of Medicine, University of Iceland, Reykjavik, Iceland \\ ${ }^{5}$ Department of Allergy and Respiratory Medicine and Sleep, Landspitali \\ University Hospital, Reykjavik, Iceland \\ ${ }^{6}$ Department of Preventive Medicine, University of Iceland, Reykjavik, Iceland
}

Twitter Follow Ragnhildur Finnbjornsdottir at @ragnhildurf

Acknowledgements The authors thank Thorsteinn Johannsson for his assistance in handling the pollution data, the Environment Agency of Iceland, and Statistics Iceland for allowing us access to their data for the study.

Contributors RGF, AO, BTE, TG and VR substantially contributed to the conception and design, obtained the data or analysed and interpreted the data; drafting of the article or revising it critically for important intellectual content; and approved the final version of the submitted manuscript.

Funding This study was supported by The Doctoral Grants of The University of Iceland Research Fund, grant number HI201090.

Competing interests The authors have completed the ICMJE uniform disclosure and the authors have no competing interests.

Ethics approval Permissions related to the data: National Bioethics Committee (ref. no. VSNb2010030008/03.7) and the Data Protection Authority (ref. no. 2010030263PS/-).

Provenance and peer review Not commissioned; externally peer reviewed.

Data sharing statement No additional data are available.

Open Access This is an Open Access article distributed in accordance with the Creative Commons Attribution Non Commercial (CC BY-NC 4.0) license, which permits others to distribute, remix, adapt, build upon this work noncommercially, and license their derivative works on different terms, provided the original work is properly cited and the use is non-commercial. See: http:// creativecommons.org/licenses/by-nc/4.0/

\section{REFERENCES}

1. Carlsen HK, Zoëga $\mathrm{H}$, Valdimarsdóttir $\mathrm{U}$, et al. Hydrogen sulfide and particle matter levels associated with increased dispensing of anti-asthma drugs in Iceland's capital. Environ Res 2012;113:33-9.

2. Finnbjornsdottir $\mathrm{R}$, Zoega $\mathrm{H}$, Olafsson $\mathrm{O}$, et al. Association of air pollution and use of glyceryl trinitrate against angina pectoris: a population-based case-crossover study. Environ Health 2013;12:38.

3. Carlsen HK, Forsberg B, Meister K, et al. Ozone is associated with cardiopulmonary and stroke emergency hospital visits in Reykjavik, Iceland 2003-2009. Environ Health 2013;12:28.

4. The World Bank Group. Motorvehicles (per 1,000 people) 2014 [cited 2014 July 22]. World Bank Open Data: free and open access to data about development in countries around the globe. http://data. worldbank.org/indicator/IS.VEH.NVEH.P3/countries/1W-IS? display=default

5. Olafsdottir S, Gardarsson S, Andradottir H. Spatial distribution of hydrogen sulfide from two geothermal power plants in complex terrain. Atmospheric Environ 2014;82:60-70.

6. Olafsdottir S, Gardarsson S. Impacts of meteorological factors on hydrogen sulfide concentration downwind of geothermal power plants. Atmospheric Environ 2013;77:185-92.

7. Olafsdottir AO, Sigurdardottir H. Reykjavik's Energy's environmental report 2013 [in Icelandic]. Reykjavik: Reykjavik Energy, 2013.

8. Hansell A, Oppenheimer C. Health hazards from volcanic gases: a systematic literature review. Arch Environ Health 2004;59:628-39.

9. Durand M, Wilson JG. Spatial analysis of respiratory disease on an urbanized geothermal field. Environ Res 2006;101:238-45.

10. Amaral AFS, Rodrigues AS. Chronic exposure to volcanic environments and chronic bronchitis incidence in the Azores, Portugal. Environ Res 2007;103:419-23.

11. Bates MN, Garrett N, Crane J, et al. Associations of ambient hydrogen sulfide exposure with self-reported asthma and asthma symptoms. Environ Res 2013;122:81-7.

12. Bates MN, Garrett N, Graham B, et al. Air pollution and mortality in the Rotorua geothermal area. Aust N Z J Public Health 1997;21:581-6.

13. Statistics Iceland. Population statistics. Reykjavik: Statistics Iceland, 2014 [cited 14 November 2014]. http://www.statice.is/Statistics/ Population/Urban-nuclei-and-zip-codes

14. World Health Organization. International classification of diseases (ICD). Geneva, Switzerland: World Health Organization [cited 30 October 2012]. http://www.who.int/classifications/icd/en/

15. Icelandic Road Administration. Traffic numbers on main roads in Iceland [in Icelandic]. Reykjavik: The Icelandic Road Administration, 2012. http://www.vegagerdin.is/vefur2.nsf/Files/Umferdartolur2005/ \$file/Umfer\%C3\%B0art\%C3\%B6lur\%202005.pdf

16. Levy D, Lumley T, Sheppard L, et al. Referent selection in case-crossover analyses of acute health effects of air pollution. Epidemiology 2001;12:186-92.

17. Maclure M. The case-crossover design: a method for studying transient effects on the risk of acute events. Am J Epidemiol 1991;133:144-53.

18. Hotelling $\mathrm{H}$. Analysis of a complex of statistical variables into principal components. J Educ Psychol 1933;24:417.

19. Akaike $\mathrm{H}$. Information theory and an extension of the maximum likelihood principle. Selected Papers of Hirotugu. Akaike: Springer, 1998:199-213. 
20. Theakston F. Air quality guidelines for Europe. 2nd edn. European Series No. 91. Copenhagen: World Health Organization, 2000.

21. R Core Team. R: A language and environment for statistical computing. R Foundation for Statistical Computing. In: R Core Team, editor. Vienna, Austria. 2014.

22. Barnett AG, Baker PJ, Dobson AJ. Analysing seasonal Data R Functions. 0.3-3 ed. Berlin, Heidelberg. 2014.

23. Bates MN, Garrett N, Graham B, et al. Cancer incidence, morbidity and geothermal air pollution in Rotorua, New Zealand. Int $\mathrm{J}$ Epidemiol 1998;27:10-14.

24. Bates MN, Garrett N, Shoemack P. Investigation of health effects of hydrogen sulfide from a geothermal source. Arch Environ Health 2002;57:405-11.

25. Chou C. Hydrogen sulfide: human health aspects. Concise international chemical assessment document 53. Geneva: World Health Organization 2003.

26. Kage S, Ito S, Kishida $\mathrm{T}$, et al. A fatal case of hydrogen sulfide poisoning in a geothermal power plant. J Clin Forensic Med 1998;5:214-15.

27. Richardson DB. Respiratory effects of chronic hydrogen sulfide exposure. Am J Ind Med 1995;28:99-108.

28. Mostaghni AA, Nabipour I, Dianat M, et al. Pulmonary symptoms and spirometric values in Kangan sour gas refinery workers. Arch Environ Health 2000;55:297-9.

29. Partti-Pellinen K, Marttila O, Vilkka V, et al. The South Karelia Air Pollution Study: effects of low-level exposure to malodorous sulfur compounds on symptoms. Arch Environ Health 1996;51:315-20.

30. Wing S, Horton RA, Marshall SW, et al. Air pollution and odor in communities near industrial swine operations. Environ Health Perspect 2008;116:1362-8.

31. Campagna D, Kathman SJ, Pierson R, et al. Ambient hydrogen sulfide, total reduced sulfur, and hospital visits for respiratory diseases in northeast Nebraska, 1998-2000. J Expo Anal Environ Epidemiol 2004:14:180-7.

32. Kilburn KH, Thrasher JD, Gray MR. Low-level hydrogen sulfide and central nervous system dysfunction. Toxicol Ind Health 2010;26:387-405.

33. Reed BR, Crane J, Garrett N, et al. Chronic ambient hydrogen sulfide exposure and cognitive function. Neurotoxicol Teratol 2014;42:68-76.

34. Kristbjornsdottir A, Rafnsson V. Cancer mortality and other causes of death in users of geothermal hot water. Acta Oncol 2015;54:115-23.

35. Kristbjornsdottir A, Rafnsson V. Cancer incidence among population utilizing geothermal hot water: A census-based cohort study. Int $J$ Cancer 2013;133:2944-52.

36. Kristbjornsdottir A, Rafnsson V. Incidence of cancer among residents of high temperature geothermal areas in Iceland: a census based study 1981 to 2010. Environ Health 2012;11:73.

37. Mathers CD, Ma Fat D, Inoue M, et al. Counting the dead and what they died from: an assessment of the global status of cause of death data. Bull World Health Organ 2005;83:171-77.

38. Carlsen HK, Gislason T, Benediktsdottir B, et al. A survey of early health effects of the Eyjafjallajokull 2010 eruption in Iceland: a population-based study. BMJ Open 2012;2:e000343.

39. Carlsen HK, Hauksdottir A, Valdimarsdottir UA, et al. Health effects following the Eyjafjallajokull volcanic eruption: a cohort study. BMJ Open 2012;2:e001851.

40. Thorsteinsson T, Hackenbruch J, Sveinbjörnsson E, et al. Statistical assessment and modeling of the effects of weather conditions on H2S plume dispersal from Icelandic geothermal power plants. Geothermics 2013;45:31-40.

41. Rothman KJ. No adjustments are needed for multiple comparisons. Epidemiology 1990;1:43-6. 